RICARD PIÉa

JOSEP MARIA VILANOVA I CLARET ${ }^{\mathrm{b}}$

ENRICO PORFIDOc

\title{
LOS EFECTOS DEL PLAN DIRECTOR URBANÍSTICO DEL SISTEMA COSTERO CATALÁN EN LA REORDENACIÓN DEL AGLOMERADO TURÍSTICO DE LA COSTA BRAVA
}

\begin{abstract}
RESUMEN
En este artículo se evalúan los efectos del Plan Director Urbanístico del Sistema Costero (PDUSC) Catalán en la reordenación del litoral turístico, una evaluación que necesita de una mínima perspectiva histórica para su resolución. La condición de este espacio es diversa según el tramo que se analiza. En esta ponencia se valora los efectos del PDUSC en la Costa Brava por ser el tramo más estudiado. De los primeros planes de los sesenta a las protestas reivindicativas de algunos movimientos sociales, pasando por los debates cívicos como los Debat Costa Brava (I y II) o la defensa de los Aiguamolls. La conclusión de este repaso será que el PDUSC es el final de un proceso de protección que debería aprovecharse para transformar el aglomerado urbanístico del turismo en ciudad. Los casos del Parc dels Estanys, de Platja d'Aro y de La Pletera de L'Estartit (Torroella de Montgrí) son dos buenos ejemplos de lo que debería ser el planeamiento futuro de la costa.

Palabras clave: aglomerado turístico, Cataluña, Costa, Costa Brava, Plan Director Costero, Turismo.

\footnotetext{
a Catedrático emérito. Instituto Hábitat, Turismo, Territorio. Universitat Politècnica de Catalunya (UPC-Barcelona Tech) y Universidad de Málaga (UMA-Andalucía Tech).ricard.pie@upc.edu

b Instituto Hábitat, Turismo, Territorio. Universitat Politècnica de Catalunya (UPC-Barcelona Tech) y Universidad de Málaga (UMA- Andalucía Tech). jmvicla@arquired.es

c Instituto Hábitat, Turismo, Territorio. Universitat Politècnica de Catalunya (UPC-Barcelona Tech) y Universidad de Málaga (UMA- Andalucía Tech).prfnrc@unife.it
}

Fecha de recepción: 26/11/2019. Fecha de aceptación: 17/2/2020. 


\title{
THE EFFECTS OF THE URBAN DEVELOPMENT MASTER PLAN OF THE CATALAN COASTAL SYSTEM ON THE REDEVELOPMENT OF THE TOURIST AGGLOMERATION OF THE COSTA BRAVA
}

\begin{abstract}
This contribution aims to assess the effects of the Catalan Coastal System Master Plan (Plan Director Urbanístico del Sistema Costero - PDUSC) in reordering the tourist coastline. To achieve this objective, a minimum historical perspective to validate its results is needed. The condition of this space is different according to the coastal section analyzed. This paper assesses the effects of PDUSC on the most studied area: the Costa Brava. Therefore, it tries to analyze all the impacts that occurred since the approval of the first plans in the sixties to the protest of current social movements, going through civic debates such as those of the Debat Costa Brava (I and II) or of the defense of Aiguamolls. The conclusion of this review is that the PDUSC is the end of a protection process that should be used to transform the urban agglomeration of tourism into a city. The cases of the Parc dels Estanys in Platja d'Aro and La Pletera in L'Estartit (Torroella de Montgrí) are two good examples of how future coastal planning should act.

KeYwords: Catalonia, coast, coastal system master plan, Costa Brava, tourism, touristic agglomerate.
\end{abstract}

\section{INTRODUCCIÓN}

Evaluar los efectos del planeamiento - territorial o urbanístico- en la configuración física del espacio turístico es difícil. Los tiempos de ejecución y desarrollo de los planes son largos y extremadamente complejos. La aplicación y desarrollo de las previsiones, a veces, son contradictorias. A las dificultades de una buena prognosis que prevea un futuro más o menos creíble, se suma una maraña administrativa y un sinnúmero de actos y procesos burocráticos que dilatan y entorpecen el proceso. Muchas veces, la aprobación llega a su fin empujada más por el cansancio que por la convicción.

El planeamiento es un enunciado, un proyecto abierto sobre el devenir de un espacio que debería servir de guía para su futuro. Nos equivocamos si pensamos que nuestros planes son previsiones fidedignas de lo que pasará. Los planes no son proyectos cerrados, sino una alternativa posible ante un futuro incierto. Es indudable que la legislación española aún está anclada en una visión unívoca del planeamiento, en una formulación cerrada y escalar, en la que, a pesar de la crisis conceptual sobre el planeamiento urbanístico que estamos sufriendo, se cree que aún es posible fijar las condiciones de desarrollo sin que haya ninguna duda al respecto.

Para evaluar los resultados de un plan se necesita el juicio del tiempo. De las propuestas del plan, antes de la información pública, hasta la última sentencia del tribunal superior de justicia, pueden cambiar las circunstancias políticas, jurídicas y administrativas y aquello que se preveía como óptimo convertirse en una propuesta sin sentido.

La consideración que se nos propone en esta Jornada Turismo-Transversal celebrada en la Cátedra Cullera, el pasado 4 de octubre de 2019, sobre los efectos de los planes del litoral en el espacio turístico, 
puede ser una pregunta imposible de responder porque aún no tenemos una perspectiva histórica suficiente. Aún estamos en la primera fase de desarrollo de aquellos y no está claro cuales serán sus efectos.

Para participar en este debate y evaluar los efectos de la ordenación del litoral nos centraremos en la Costa Brava por ser uno de los espacios más estudiados del litoral catalán. La batalla por la protección de este tramo de costa no resultará de la aprobación del Pla Director Urbanístic del Sistema Costaner (PDUSC) sino de una serie de actos y movilizaciones que arrancan en los setenta en el I Debat Costa Brava (I-DCB-76) y que ahora continúan con las protestas impulsadas por la plataforma reivindicativa SOS Costa Brava (SOS-CB-19). La cuestión que nos ocupa empieza en los sesenta con la aprobación de varios planes generales municipales de ordenación urbana redactados por la Comisión de Urbanismo de la Provincia de Gerona y ahora se resuelve con episodios como la desclasificación y protección de los salobrales de La Pletera en L'Estartit y en su reconocimiento internacional. ${ }^{1}$

El PDUSC es seguramente un documento final, de cierre y conclusión de algunos debates y controversias que se han arrastrado desde la época franquista y que, en algunos casos, aún están por resolver. Por esta razón, para juzgar los efectos del PDUSC en la Costa Brava nos apoyaremos en la historia urbanística del litoral gerundense, a partir de 1956, con la promulgación de la Ley de Régimen del Suelo y Ordenación Urbana (LS-56) hasta el premio al municipio de Torroella de Montgrí por sus actuaciones en los humedales de La Pletera (Pié, 2004).

\section{BREVE Historia DEL DESARROLlO Y POSTERIOR PROTECCIÓN de los últimos espacios libres de la Costa Brava}

Para empezar, evaluaremos los efectos de la aplicación de la Ley de Régimen del Suelo y Ordenación Urbana (LS-56), dejando fuera algunos episodios de finales del xix y principios del xx, los ensanches suburbanos que podemos descubrir en las ciudades de la industria corchera de Palamós y Palafrugell o el proyecto de reforma interior de Sant Feliu de Guíxols, porque son fenómenos más propios de la ciudad industrial que de la ciudad turística posterior. Aquellos años fueron tiempos de prosperidad económica que se reflejó en el crecimiento urbano de estas ciudades y en la construcción de algunas infraestructuras de comunicación como las dos líneas de ferrocarril de vía estrecha de Girona a Sant Feliu de Guíxols, (1889) y de Banyoles y Girona a Palamós (1887) que muestran la fuerza industrial de estos centros.

El paso del crecimiento suburbano en mancha de aceite, impulsado por la industrialización, al crecimiento por paquetes, por piezas autónomas, empieza a mediados del siglo xx, veinte años más tarde del final de la Guerra Civil, cuando el turismo aparece como la única oportunidad económica para recuperar la maltrecha economía de postguerra y superar los disparates económicos de la autarquía.

1 El Ayuntamiento de Torroella de Montgrí recibió, el pasado mes de setiembre, uno de los premios mundiales de la Sustainable Cities And Human Settlements Awards, que convoca el Global Forum on Human Settelments (GFHS), vinculado a las Naciones Unidas. La concesión del galardón en la categoría Global Low-Carbon Ecological Scenic Spot premió la recuperación del humedal de La Pletera como un modelo de desarrollo sostenible y resiliente. 
La historia urbanística-turística de la Costa Brava se puede dividir en cinco etapas (en cuatro más una), en una secuencia en la que cada periodo empieza antes de que termine el anterior:

1. De la promulgación de la Ley de Régimen del Suelo y Ordenación Urbana (LS-56) a las primeras elecciones democráticas municipales de 3 de abril de 1979, el periodo franquista de especulación y malbaratamiento del medio.

2. De la publicación del libro "Le Paysage humain de la Costa Brava" de Yvette Barbaza (1966), a la celebración del I Debat Costa Brava de 1976 (IDCB-76) y el Congrés de Cultura Catalana de 1975/77 (CCC-75/77), pasando por el libro "NATURA, ÚS O ABÚS? Llibre blanc de la gestió de la Natura dels Països Catalans", editado por Ramon Folch y Josep Peñuelas y publicado por la Societat Catalana d'Història Natural, en definitiva, por los primeros movimientos reivindicativos del territorio y el paisaje.

3. De la revisión de los planes urbanísticos municipales promovidos por la Generalitat provisional presidida por Josep Tarradellas, al Debat Urbanístic de la Costa Brava (DUCB-90), organizado por el Colegio de Arquitectos de Cataluña (1990), o dicho en otras palabras, de reordenación de la herencia franquista.

4. De la celebración del II Debat Costa Brava de 2004 (IIDCB-04) a la aprobación del Pla Director Urbanístic del Sistema Costaner de 2005 y la movilización de SOS Costa Brava (2019), o de autocrítica sobre lo hecho y de la necesidad de terminar definitivamente con los compromisos especulativos del pasado.

5. Capítulo aparte, merece una mención especial la Declaració de Paratge Natural dels Aiguamolls de l'Empordà de 1983 y el premio internacional por la recuperación de La Pletera.

\section{De LA Ley del SUelo de 1956 a los últimos Planes DEL PERIOdO FRANQUista}

La revolución industrial en las ciudades costeras catalanas se produce durante el xix en base al excedente económico de una agricultura floreciente que financiará la industrialización y desarrollo urbano de la costa. La transformación de este territorio en un espacio para el ocio y el descanso se produce más tarde, a finales del xix y principios del xx.

El paso de una sociedad agrícola a una sociedad industrial da pie al éxodo de una parte importante de la población rural del campo a la ciudad y a la formación de grandes concentraciones urbanas, que cambiaron el uso y disfrute del territorio. Las nuevas clases urbanas acomodadas volvieron temporalmente al campo como alternativa a los inconvenientes de la ciudad y para gozar de la naturaleza durante las vacaciones. La estancia en el campo se convierte en otra manera de disfrutar del tiempo libre y de entender el territorio. La villégiature — la posesión de una vivienda señorial para una estancia en la costa-, primero, y la segunda residencia, después, se convierten en otra forma de gozar de la naturaleza. El campo deja de ser el lugar del trabajo agrícola para convertirse en una ventana al territorio y con ello, un lugar para el ocio y el estío.

Las fórmulas legales y urbanísticas para resolver estos cambios, desde la mitad del xix hasta finales del primer tercio del siglo xx, fueron las leyes de Ensanche y Extensión; las de Saneamiento y Mejora Interior; y la reforma de la Ley de Régimen Local de Calvo Sotelo, legislaciones parciales para afrontar 
los retos que planteaba el crecimiento de la ciudad industrial. Para el conjunto de estas legislaciones, la ordenación de la ciudad pasaba por la extensión del núcleo histórico con ensanches suburbanos de dimensiones contenidas y por la reforma interior para el saneamiento de los barrios históricos más degradados con la abertura de vías que actuaban a la manera del bisturí en las manos del cirujano.

La primera ley urbanística moderna fue la Ley del Suelo de 1956 (LS-56), que intenta superar el puzzle legislativo anterior, propone una regulación integral que cubra todo el territorio y una categorización del suelo según su vocación de futuro. Para resolver el primer objetivo, se propone una cascada de planeamiento que va del plan nacional al plan parcial, pasando por la escala provincial, comarcal y municipal, y para cubrir el segundo, tres categorías urbanísticas: suelo urbano, de reserva y rústico, una clasificación pensada casi exclusivamente para el crecimiento urbano.

La competencia para la formulación de los planes municipales era de las Diputaciones, los Ayuntamientos o las comisiones de urbanismo (Art. 24.1). "No obstante, aquéllas (Diputaciones y Ayuntamientos) podrán encomendar la formulación a la Comisión provincial de Urbanismo, y los Ayuntamientos a esta o a la Diputación" (Art.24.2). Esta posibilidad dará pie a que la Comisión Provincial de Urbanismo de Girona redacte los primeros planes generales municipales de, prácticamente, todo el litoral.

A partir del 1956, la Comisión de Urbanismo decidirá el futuro de la Costa Brava; el plan de L'Escala se aprobará en 1956; el de Roses y Blanes, en 1958; el de Torroella de Montgrí, Palamós, Sant Antoni de Calonge y Platja d'Aro, en 1959 y el de Palafrugell-Calella-Tamariu, en 1962, hasta cubrir la práctica totalidad del frente marítimo de la Costa Brava (Ramos, 2015). Los funcionarios de la Comisión interpretarán con estos planes que la iniciativa recae en la Administración. Urbanísticamente, todos los planes se resuelven con el mismo patrón. Más allá del reconocimiento del núcleo histórico y sus crecimientos, se delimitará una banda urbanizable de baja densidad de unos 200/300 m de anchura que se extenderá a lo largo de todo el litoral. Con este gesto, más intuitivo que racional, los redactores pondrán en el mercado inmobiliario todo el frente de mar, sin importarles las dificultades topográficas ni los valores ambientales de la costa. En la Memoria Justificativa del Plan de Cadaqués, por ejemplo, se reconoce el estancamiento económico y demográfico que sufren el municipio y la importancia del turismo como proyecto de futuro.

No se puede cargar a estos planes las culpas del desastre urbanístico posterior. El patrón urbanístico que se sigue no es malintencionado, pero, tal como se ha demostrado posteriormente, tampoco es inofensivo. Las expectativas urbanísticas generadas por aquellos planes darán pie a una avalancha posterior de planeamiento parcial especulativo para atraer al capital extranjero que había entrado en España a partir de la aprobación del Plan de Estabilización de 1959.

A partir de aquel momento todo cambiará, el Plan Parcial se convertirá en la figura adecuada para desarrollar aquellas expectativas. Expectativas que, a través de ciertas interpretaciones y modificaciones, acabarán por legitimar unas densidades y alturas que no estaban previstos en aquellos planes de ordenación. El abuso especulativo a partir de los sesenta es tan escandaloso que, en 1968, el Gobernador Civil de Girona, Víctor Hellín, que preside la Comisión de Urbanismo Provincial, aprueba una norma especial para limitar las alturas de la edificación. Una regulación que, en algunos municipios, 
sirvió para aumentar la edificabilidad. La nueva regulación fijaba una altura máxima menor que la que se aplicaba en la fachada marítima pero muy superior que se aplicaba a la edificación de baja densidad. En Platja d'Aro el volumen edificable del llano se doblará gracias al aumento de la altura de toda la edificación interior, tergiversando con ello los objetivos de la norma (Barba y Pié, 1988).

El modelo urbanístico del turismo dejó de ser el de la ciudad jardín, como fórmula adaptable a cualquier topografía, para ser substituida por edificación en bloque abierto, tal como se estaba haciendo en Montecarlo, tal como defendía el planeamiento urbanístico del momento. Aunque no había una especial preocupación por la cobertura legal de cualquier tipo de operación especulativa —la corrupción administrativa está a su servicio—, el mercado internacional pedía una mínima seguridad jurídica que obligó a los promotores y a la administración a tramitar diversas figuras de planeamiento para "legalizar" aquello que no tenía una cobertura jurídica suficiente.

La revisión especulativa del planeamiento municipal se producirá impunemente hasta la muerte del dictador. En algunos ayuntamientos se aprobarán modificaciones y legalizaciones especulativas hasta el último momento. Muchos de los derechos urbanísticos conseguidos en este período se habrán logrado con malas artes, con la desvergüenza que da un poder basado en la corrupción. En estos momentos, el planeamiento urbanístico tiene más de acta notarial y de blanqueo de los estropicios urbanísticos llevados a cabo que de proyecto urbano y territorial para la comunidad.

En menos de quince años, de principios de los sesenta a mediados de los setenta, el urbanismo español habrá culminado su obra especulativa. El negocio inmobiliario descubrirá dos inversiones muy apetecibles: en la ciudad, la vivienda para las clases populares y en el litoral, el turismo de masas. El primero colmará las pocas aspiraciones que se podían permitir las clases populares, el acceso a la propiedad cuando se sale de la miseria, y el segundo, los sueños reparadores de unas vacaciones para las clases trabajadoras de aquí y de fuera.

El fracaso económico de la política autárquica que seguían los primeros gobiernos franquistas y la aprobación del Plan de Estabilización (1959) arrinconarán la incipiente legislación urbanística (LS56) y, tal como decía Francisco Jordâo, parafraseando el título de su libro, España (se pone) en venta (Jordâo, 1979). La recuperación económica es el objetivo principal del país y todo lo que atraiga actividad y capitales se admitirá como bueno.

\section{El DESPERTAR SOCIAL ANTE LA DESTRUCCIÓN MEDIOAMBIENTAL y PAISAGISTA DE la Costa BRAVA}

La reacción ante este desaguisado se produce a partir de mediados de los setenta. Antes de estas fechas, en 1966, se publica en Francia el trabajo de investigación de Yvette Barbaza sobre el paisaje de la Costa Brava. Aunque no es un libro reivindicativo, es el aviso de que algo está pasando, un cambio que afectará al uso y percepción del territorio. El libro de Barbaza no entra en el futuro urbanístico que le depara el turismo, sino en los valores de este territorio y sobre los riesgos y oportunidades que se plantea. Barbaza no imagina que le deparará el devenir, pero avisa de lo que puede perderse. 
El final de la posguerra europea hasta la crisis petrolera de los setenta fue un periodo de crecimiento económico que los expertos bautizan de "glorioso", pero también de reflexión crítica sobre su futuro. El mayo del 1968 fue, seguramente, el preámbulo adelantado del fin de fiesta de una sociedad del bienestar que rozaba la opulencia. La fábrica dejó de ser el campo de batalla de las clases populares para centrarse en las cuestiones de dominio y uso del espacio. La revuelta social dejó de pensar en la fábrica para dirigir su mirada hacia la ciudad, "Le droit à la ville" (Lefebvre, 1968), y denunciar la mercantilización de las conquistas sociales que se habían producido con el desarrollo de la sociedad del bienestar.

Las preocupaciones que aparecen a partir de los sesenta tienen otras prioridades, los límites del crecimiento (Meadows et al, 1972) —nombre del informe que presenta el Club de Roma en 1973 - o la preocupación por la durabilidad que recoge el informe de la Comisión Brundtland (1987). La publicación de libros como el de Rachel Carson, "Silent Spring" (1962) despiertan la preocupación por el medio.

Es cierto que los movimientos vecinales no tuvieron una presencia significativa en los municipios turísticos. El movimiento vecinal en Cataluña empieza en Barcelona, en el Poble Nou, con el Concurs del Contraplà de la Ribera, convocado en 1971 por el Colegio de Arquitectos de Cataluña y Baleares en contra de la ordenación del Sector Marítimo Oriental redactado por el arquitecto Bonet Castellana para el conglomerado de industrias que ocupaban el frente marítimo de este sector. La preocupación medioambiental, por el contrario, aparecerá con más fuerza en estos municipios.

Los dos eventos que recogerán estas preocupaciones serán: el Congrés de Cultura Catalana (CCC) y el I Debat de la Costa Brava (IDCB). El primero fue un acontecimiento promovido por el Colegio de Abogados que se desarrolló en todo el ámbito de los Països Catalans. El segundo, promovido por la revista Presència, se centró en la crisis de la Costa Brava. Los objetivos del primero fueron la normalización de la lengua y la cultura catalana, y los del segundo, la denuncia y reivindicación "urbanística" de la costa gerundense.

El CCC se organizó en veinticinco ámbitos de trabajo en los que encontraron cobijo las preocupaciones territoriales con debates y encuentros seminales como fueron los de la Seu d'Urgell, sobre la división territorial de Cataluña, o el del Prat de Llobregat, sobre la macrocefalia de Barcelona. La Societat Catalana d'Història Natural lideró los temas ambientales, publicando un libro, "NATURA, ÚS O ABÚS? Llibre blanc de la gestió de la Natura dels Paísos Catalans" (Folch y Peñuelas, 1976) —editado por Ramon Folch y Josep Peñuelas — seminal, que marcará el despertar medioambiental del país.

Los primeros movimientos reivindicativos que se dan en la Costa Brava se producen a inicios de 1976 contra el mal estado del río Ter por culpa de los vertidos de la fábrica Torras Hostench, situada río arriba, en la salida norte de la ciudad de Girona. Estos movimientos se extendieron, posteriormente, en defensa de los humedales del litoral, con resultados contradictorios. Mientras que los humedales del Alt Empordà se salvaron gracias a la intervención directa del primer gobierno autonómico catalán, se abandonaron a su suerte los del Baix (Pié, 2018).

Así empezó la deconstrucción urbanística de algunas de las operaciones especulativas más relevantes heredadas del franquismo, comprando el suelo para recalificarlo de parque natural. Una intervención puntual que no estuvo acompañada de un plan que fuera más allá y que garantizara la defensa de 
todo el sistema lagunar del frente marítimo de la Costa Brava. La desafección especulativa del suelo y la reducción de la intensidad edificatoria del edificable se dejó en manos del planeamiento municipal. Los planes de ordenación del litoral llegaron mucho más tarde, después de algunas batallas políticas en las que no siempre ganó el territorio.

La cuestión urbanística en los últimos años del franquismo giró en torno al desarrollo del planeamiento municipal. En la comunicación presentada por Juli Esteban en el I-DCB-76, en nombre de la Oficina de Información Urbanística del Colegio de Arquitectos de Cataluña y Baleares (OIU), se explicaba la deriva técnica y jurídica que había sufrido la ordenación urbanística municipal. El planeamiento que se tramitó durante este periodo tenía el formato del plan parcial a pesar de que en muchas ocasiones modificaba aprovechamientos y delimitaciones que solo se podían afrontar desde el planeamiento general. Los planes parciales fueron el instrumento para incrementar la urbanización e intensificar la mancha edificada (Esteban, 1978).

\section{LA REVISIÓN DEL PLANEAMIENTO LLEVADO A CABO POR LOS PRIMEROS AYUNTAMIENTOS DEMOCRÁTICOS}

La revisión del planeamiento urbanístico de la Costa Brava tuvo una génesis especial. La Generalitat provisional, aprovechó su condición de mancomunidad de diputaciones, para desarrollar una de las pocas competencias urbanísticas que le otorgaba la legislación, la aprobación definitiva del planeamiento urbanístico supramunicipal. Lluís Cantallops, el primer Director General de Urbanismo de la Democracia, aprovechó esta circunstancia para promover una serie de planes supramunicipales que debían resolver el planeamiento urbanístico de los principales municipios de la Costa Brava.

La llegada de Jordi Pujol a la presidencia de la Generalitat acabó con esta experiencia. El nuevo director, Joan Antoni Solans, prefirió aplicar una política paternalista y fiscalizadora desde las comisiones de urbanismo antes que promover un planeamiento territorial que orientase el quehacer urbanístico desde la responsabilidad de cada institución afectada. El cambio de estrategia de la Dirección General fue una oportunidad perdida, que hubiese podido dar lugar a un planeamiento supramunicipal construido desde la base. Pié (1989) lo explicaba de la siguiente manera:

Els ajuntaments van participar en aquesta iniciativa, renunciant a part de les seves competències urbanístiques $i$ obligant-se a entendre's amb els veïns, portats pel valor polític $i$ racional que tenia aquesta proposta. Les primeres eleccions autonòmiques van canviar l'orientació política del govern de la Generalitat $i$ es van trencar els pactes anteriors. El govern convergent entenia que el planejament urbanístic era una qüestió municipal i no autonòmica, raó per la qual va propiciar la disgregació dels plans intermunicipals i moderà els seus continguts. En el termini d'un any, la revisió dels plans d'urbanisme va deixar de ser un projecte nacional, de compromís entre la Generalitat, els Ajuntaments $i$ els tècnics, per convertir-se en un afer municipal (Pié, 1989, p. 37).

Si en el I-DCB-76 se denunció la degradación y peligros que sufría la Costa Brava, en el Debat urbanístic sobre la Costa Brava (DUCB) se valoró la respuesta que se había dado en relación a los objetivos planteados en el I-DCB-76. En esta evaluación se aplicaron algunos criterios que no se correspondían 
exactamente con la realidad social de la Costa Brava. La población de estos municipios no se comportó como los ciudadanos de las grandes aglomeraciones urbanas.

Los movimientos vecinales del Área Metropolitana de Barcelona en los últimos años del franquismo habían elaborado un cuadro reivindicativo que se convirtió en el programa urbanístico de los primeros ayuntamientos democráticos. En los municipios turísticos no existía este tipo de movimientos. La mayoría de residentes dependían de la economía turística y, por ello, veían con preocupación cualquier actuación que afectara al mercado inmobiliario. El debate social sobre el futuro oscilaba entre aquellos que defendían la necesidad de reformular el modelo, en algunos casos trabajadores y empresarios del sector, y aquellos otros que, temerosos de lo que pudiera ocurrir en el futuro, apostaban por exprimir el producto turístico hasta la extenuación, actitud que compartían los especuladores, a veces, con la aquiescencia indisimulada de la población.

En el II-DCB-1976 se denunció el fracaso o, mejor dicho, la insuficiencia de la revisión del planeamiento urbanístico municipal redactado en los años ochenta. Oriol Nel·lo en el artículo de presentación del PDUSC (2006) señala que entre los años 1974 i 1993, según Carolina Martí de la Unitat de Geografia de la Universitat de Girona, se urbanizaron 300 ha al año, casi una hectárea (un campo de futbol) al día. En la ponencia que presenté en la sesión celebrada en el teatro municipal de Roses me correspondió defender aquellos planes. A menudo se olvida que el paso del régimen franquista al democrático se hizo pacíficamente a través de lo que se bautizamos como la Transición Democrática. Si se hubiera producido una ruptura política, seguramente, se habría podido empezar de nuevo, sin los hándicaps del pasado. La revisión del planeamiento urbanístico municipal tuvo que partir del planeamiento franquista y buscar las grietas del pasado para reducir la mancha de crecimiento y afrontar la reordenación de la ciudad consolidada.

El resultado de esta primera revisión fue un tanto agridulce porque aquello que no se eliminó se convirtió en una bomba especulativa con espoleta retardada, un campo de minas que se podía activar en cualquier momento. No siempre se pudo desclasificar los suelos urbanizables ya sea porque estaban a medio hacer, con propietarios y usuarios que no eran responsables de los desaguisados que se habían cometido, o porque los derechos urbanísticos estaban más o menos consolidados.

A pesar de todo, la revisión del planeamiento urbanístico catalán de los ochenta fue un éxito, sobre todo si se compara con las llevadas a cabo en otras regiones españolas, en las que, con la excusa de evitar indemnizaciones millonarias, se legitimó un planeamiento condujo a un segundo periodo especulativo, en los noventa, que no pudo justificarse por culpa de los déficits democráticos que había sufrido el país.

\section{El Pla Director Urbanístic del Sistema Costaner. Fin de fiesta}

La aprobación en 2005 del Pla Director Urbanístic del Sistema Costaner (PDUSC) fue el final de trayecto de la reordenación urbanística del litoral. El mérito de este desandar urbanístico fue de muchos, de las instituciones democráticas y sus representantes, Generalitat, Gobierno de España y ayuntamientos, así como de los movimientos sociales y las plataformas profesionales como el Colegio de Arquitec- 
tos o científicas como la Universidad. El PDUSC fue el punto y final de un proceso de recuperación de la costa, comandado por la Generalitat, gobernado por el tripartito, con el que el gobierno catalán quiso asegurarse la defensa definitiva de los últimos rincones no urbanizados del litoral.

El planeamiento supramunicipal en Catalunya, redactado durante los ochenta del siglo pasado no había tenido mucha suerte. Los problemas generados por algunos de ellos, como el non nato Pla Residus (1990), ${ }^{2}$ los convirtió en un calvario que la administración autonómica intentó evitar. Lo que había de ser un instrumento de ayuda a la ordenación del país se convirtió en un dolor de cabeza, políticamente aciago. Por esta razón, los planes territoriales decayeron, se vaciaron de contenido, y perdieron su función. Era más fácil actuar directamente, según las circunstancias, que con un plan. En el periodo gobernado por el tripartito se intentó un planeamiento más sencillo, sin estridencia, que cubriera los mínimos necesarios para orientar correctamente las líneas de desarrollo del planeamiento urbanístico municipal. Es así como se ha de leer el PDUSC y todo el sistema de planeamiento territorial vigente que se aprobó en este periodo.

Orio Nel·lo (2006) justificó la necesidad del PDUSC con un diagnóstico cuantitativo preocupante. Para él, era urgente la actuación de la administración autonómica para obturar la hemorragia urbanística que se producía en la costa y alcanzar cuatro objetivos básicos:

a) Urbanístics: evitar la consolidació d'un continu edificat que podria arribar a cobrir una part substancial de la línia de costa.

b) Patrimonials: preservar els espais costaners pels seus valors paisatgístics, culturals $i$ simbòlics.

c) Ambientals: possibilitar la preservació d'un mitjà particularment fràgil com el costaner $i$ assegurar la continuitat entre els ecosistemes terrestres i marítims.

d) Econòmics: gestionar l'espai costaner com a recurs essencial per al desenvolupament econòmic $i$, en particular, per a I'activitat turística (Nel·lo, 2006, p. 32).

Unos objetivos que aun siendo bastante genéricos fueran suficientes para legitimar la protección definitiva de los últimos espacios libres que quedaban en el litoral. Esta protección se conseguía con una clasificación relativamente sencilla de los suelos afectados por el plan. Los suelos no urbanizables así como los urbanizables no delimitados se convirtieron en suelos no urbanizables costeros, que no podían urbanizarse salvo en raras excepciones (para equipamientos o servicios); los delimitados con planeamiento parcial aprobado se mantenían como tales, mientras que los que no tenían plan parcial aprobado debían situar sus espacios libres lo más cerca posible de la línea de costa y adecuar la tipología de las edificaciones al paisaje; finalmente, se mantenía la ordenación del suelo urbano, tanto del consolidado como del no consolidado. Esta clasificación pone de manifiesto la extrema prudencia del plan. Si

2 El proyecto del Pla de Residus de Catalunya se aprobó el 22 de enero del 1990 y se retiró el 22 de setiembre. En este plan se preveía la instalación de una incineradora y un vertedero en una de las comarcas económicamente más deprimida del país, la Conca de Barberà. La reacción del territorio ante esta decisión fue inmediata e inesperada y en algunos momentos violenta. En Valls, un pequeño grupo apedreó el helicóptero que transportaba a Jordi Pujol. A partir de aquel fracaso se evitó la redacción de planes supramunicipales que pudieran dar pie a cualquier controversia social. 
contraemos el documento, podríamos decir que la propuesta consistía básicamente en retirar las competencias urbanísticas municipales del suelo libre del litoral poniéndolo bajo la tutela de la Generalitat.

En el II-DCB-2004 defendí, en una ponencia titulada "Ara toca fer ciutat", la necesidad de pasar del aglomerado turístico a la necesidad de hacer ciudad (Pié, 2005). Si resumimos el PDUSC en términos estrictamente cuantitativos, siempre se podrá lamentar que no se hayan eliminado todas las expectativas especulativas que amenazan a la costa, tal como sucede con las quejas de la asociación "SOS Costa Brava". Si entendemos que estamos en otra fase, ante el reto de transformar el arracimado turístico en ciudad, valoraremos muy positivamente los pasos dados por el PDUSC pero nos preguntaremos si aquello es suficiente, si no deberíamos haber ido más lejos y aprovechar la oportunidad para transformar el conglomerado urbanístico en ciudad.

Durante estos años hemos tenido la oportunidad de trabajar en la ordenación de algunos municipios turísticos y la posibilidad de proponer y proyectar dos operaciones que han ido en esta dirección, la ordenación de dos espacios naturales de primera línea de mar convertidos en una infraestructura verde para la futura ciudad.

El primero de estos dos proyectos es la transformación del Parc dels Estanys de Platja d'Aro en un parque urbano inundable que sirve para rehacer el ciclo del agua, convirtiendo el corazón del mismo en un espacio para la laminación y control de los grandes aguaceros, y el segundo, la desurbanización del salobrar de La Pletera de Torroella de Montgrí en el último humedal salvado de la especulación urbanística (Pié et al., 2018). En las dos propuestas se ha ido más allá de la simple protección del lugar. La defensa de un espacio libre costero se ha convertido en un proyecto de ordenación territorial, en un caso, de diseño de una infraestructura verde, y en otro de recuperación del frente de mar.

El Parc dels Estanys es un proyecto de reconstrucción del ciclo del agua del llano aluvial del Riudaura, con las reservas de suelo previstas en el Plan General para construir una zona verde, un gran parque urbano de contención del crecimiento, convertido en un regulador hidráulico de la cuenca fluvial. La defensa de un espacio libre se ha llevado a cabo transformando lo que estaba planteado como parte de un hipotético green belt en una infraestructura estratégica para luchar contra las inundaciones que se producen cuando hay un gran aguacero o que se puedan producir con el cambio climático.

La recuperación de La Pletera es una operación más clásica, evitar la urbanización y edificación de un saladar y restituir su condición ambiental. Los problemas en este caso han sido muy distintos. La batalla ha sido larga y compleja y empezó con una primera derrota en la revisión del Plan General de 1983. En ella se eliminaron las expectativas de edificación de todo el llano aluvial del Ter a cambio de permitir la edificación del frente de mar, de una zona pantanosa de gran valor ecológico. En la revisión de 2002, uno de los objetivos principales del plan fue enmendar este error y salvar La Pletera. La batalla jurídica fue demostrar que este suelo nunca debía haberse urbanizado porque, de acuerdo con las condiciones que establecía la Ley de Costas, formaba parte del dominio público de la zona marítimo terrestre del lugar.

La revisión del planeamiento urbanístico general de 2002 consiguió la clasificación de este suelo como no urbanizable y como parte indisoluble del dominio público de la zona marítimo terrestre de los humedales y bocana del Ter. Más tarde, el Ayuntamiento y la Universidad de Girona consiguieron 
un programa LIFE para llevar a cabo los trabajos de des-urbanización del humedal y de restitución del sistema ambiental. La culminación de este proceso ha llegado el 2019, con el final de los trabajos y el reconocimiento internacional de su ejemplaridad.

El repaso histórico del devenir urbanístico de la Costa Brava nos ha mostrado un recorrido más complejo del que resultaría de evaluar exclusivamente los efectos prácticos del PDUSC. La batalla para la protección de este tramo de costa empezó el mismo día en que se aprobó el primero de los planes urbanísticos franquistas, continuó con diversos episodios de debate y actuación, y se mantiene con movimientos reivindicativos como SOS Costa Brava. El final de este proceso, sin embargo, no se completará hasta que pasemos de discutir sobre protecciones y reservas para hablar de proyectos; en otras palabras, hasta que pasemos a hablar de como transformar el conglomerado turístico que ha recubierto la costa en ciudad. Los proyectos de Platja d'Aro y Torroella de Montgrí son ejemplos de lo que nos pide la Costa Brava cuando pensamos en que debería ser la ciudad turística del mañana (Pié, 2004).

Nota final: Después de la Jornada de la Cátedra de Cullera celebrada el 4 de octubre de 2019, se ha producido un último episodio que confirma alguna de las consideraciones formuladas en este escrito. El día 2 de diciembre de 2019, la Generalitat de Catalunya aprobó otro plan, titulado "Pla Director Urbanístic de Revisió dels sòls no sotenibles del Litoral Gironî", que confirma los argumentos presentados en este artículo. Las sentencias favorables a las propuestas del PDUSC han envalentonado a la Generalitat, animándola a presentar otro plan con el que cerrar definitivamente las expectativas especulativas heredadas del periodo franquista. La cuestión es la misma, aún estamos resolviendo los problemas heredados de aquel periodo. Ahora sería el momento de afrontar la ordenación de la Costa Brava como un sistema urbano con expectativas para devenir una ciudad.

\section{REFERENCIAS}

Barba Casanovas, R. y Pié Ninot, R. (1988): Espontaneísmo, recursos y problemas del turismo costero catalán. Revista Urbanismo. COAM n ${ }^{\circ}$. Madrid: Colegio Oficial Arquitectos de Madrid.

Barbaza, Y. (1966): Le paysage humain de la Costa Brava. Paris: Ed. Armand Colin.

Carson, R (1962): Silent Spring. Boston: Houghton Mifflin Harcourt.

Coromines, E. (1989): La revisió del model de creixement dels anys 60-70. Debat Urbanístic Costa Brava. Girona: Col·legi d'Arquitectes de Catalunya. Demarcació de Girona.

Esteban, J. (1978): Acció Urbanitzadora a la Costa Brava. I Debat Costa Brava. Girona: Cámara Oficial de Comerç i Industria.

Folch, R. y Peñuelas, J. (Eds.). (1976): Natura, ús o abús? Llibre blanc de la gestió de la Natura dels Països Catalans. Barcelona: Societat Catalana d'Història Natural.

Jordâo, F. (1979): España en venta: la compra de suelos por extranjeros y colonización de campesinos en la Costa del Sol. Madrid: Ed. Ayuso.

Lefebvre, H. (1968): Le droit à la ville. Paris: Éditions Anthropos.

Meadows, D., Meadows, D., Randers, J. y Beherens, W.W. (1972): The limits to growth. New York: Universe Book. 
Nel·lo, O. (2006): El Pla director urbanístic del litoral de Catalunya (PDUSC). Espais, 52. Barcelona: Departament de Política Territorial i Obres Públiques. Generalitat de Catalunya.

Pié, R. y Barba, R. (1983): Estudis Urbans: Castell-Platja d'Aro, Sant Feliu de Guixols, Santa Cristina d'Aro. 1981. Barcelona: Departament de Política Territorial i Obres Públiques. Generalitat de Catalunya.

Pié, R. (1989): Els Plans Generals de Sant Feliu de Guixols i Platja d'Aro, una revisió inacabada. Debat Urbanístic Costa Brava. Girona: Col-legi d'Arquitectes de Catalunya. Demarcació de Girona.

Pié, R. (2004): Medio y paisaje. Los argumentos centrales del nuevo planeamiento urbanístico. Le revisión del Plan General de Torroella de Montgrí. Revista Cartas Urbanas, 9. Las Palmas de Gran Canarias: Universidad de Gran Canarias.

Pié, R. (2005): Ara toca fer ciutat. II Debat Costa Brava. Girona: Col-legi Arquitectes de Catalunya. Demarcació de Girona.

Pié, R., Vilanova, J.M., Díaz, P. y Zahonero, A. (2018): “Salvem la Pletera”. Crónica d'un impossible. (Des)fer paisatges. Barcelona; Observatori del Paisatge de Catalunya.

Ramos, C. (2015): Costa Brava, los retos urbanísticos del turismo de masas. La huella de la ciudad jardín y algunos principios racionalistas en el tejido turístico de masas. QRU 5-6. Barcelona. Grup recerca urbanisme (GRU). Departament Urbanisme i Ordenació del Territori. UPC.

Cómo citar este artículo:

Pié, R., Vilanova i Claret, J. M., Porfido, E. (2021). Los efectos del plan director urbanístico del sistema costero catalán en la reordenación del aglomerado turístico de la Costa Brava. Cuadernos de Geografía, 106, 31-44. https://doi.org/10.7203/CGUV.106.16153

\section{(c) $(1) \Theta$}

Este obra está bajo una licencia de Creative Commons Reconocimiento-NoComercial-SinObraDerivada 4.0 Internacional. 